\title{
TOWARDS THE CLASSROOM OF THE FUTURE: NEW IDEAS AND PROPOSALS
}

\author{
I. Payá Zaforteza ${ }^{1}$, N. Matarredona Desantes ${ }^{1}$, P. Fuentes-Durá1, T. Pellicer \\ Armiñana $^{1}$, S. Asensio Cuesta ${ }^{1}$, I. Kuster Boluda ${ }^{2}$, N.M. Vila López ${ }^{2}$, J.L. Denia \\ Ríos $^{1}$ \\ ${ }^{1}$ Universitat Politècnica de València (SPAIN) \\ ${ }^{2}$ Universitat de València (SPAIN)
}

\begin{abstract}
The Bolonia process and the development of the European Higher Education Area (EHEA) motivated a deep change in the teaching-learning process which has pushed for new teaching methodologies as well as for the development of transversal competences (e.g. leadership, team building).

New teaching approaches and new competences require new learning spaces. However, the classroom has not experienced any significant change.

Within this context, this paper will present the preliminary results of an experience developed at the School of Civil Engineering of the Universitat Politècnica de València in Spain, where a traditional classroom is being transformed to create a new inspiring space that promotes the acquisition of both specific and transversal competences. The new classroom, which has been named as the "aula del futuro" (classroom of the future), has been designed with a bottom to top process.

Results show that accessibility, flexibility of the space and the use of natural light are the most valued classroom requirements and that it is also important for the students to have a welcoming area at the classroom entrance as well as a leisure zone to promote relaxation and reflection. The paper will present the results of all the classroom definition process and the details of the implemented classroom design.
\end{abstract}

Keywords: Transversal competences, new learning spaces, innovation.

\section{INTRODUCTION}

The Bolonia process [1] and the development of the European Higher Education Area (EHEA) motivated a deep change in the teaching-learning process which: (a) moved from a teacher centered approach to a student centered approach, and (b) had to empower the student to develop lifelong learning skills. Building the EHEA is a big challenge and has pushed for the implementation of new teaching methodologies and for the development of transversal competences (e.g. leadership, teambuilding) which were not considered in traditional higher education.

New teaching approaches and new competences require new learning spaces. However, the classroom, which is the space where most of the teaching-learning process happens, has not experienced any significant change.

Aware of both, this paradigm shift and the need for new spaces, a multidisciplinary team of professors of the Universitat Politècnica de València (UPV henceforth) and the Universitat de València (UV henceforth) from different areas (architecture, civil engineering, industrial design, marketing, ergonomics) joined forces to transform a traditional classroom from the School of Civil Engineering into an inspiring learning space. The new space design is based on the background of all the team members, but fundamentally springs from a particular experience in creating a new learning space at Princeton University, US (Garlock and Paya-Zaforteza, [2]) where a classroom was transformed into a colourful space designed by the professors and inspired by the classrooms of kindergartens and nursery schools. The space was decorated with the participation of the students and the experience was very successful, but a survey revealed that some enhancements of the furniture were required to make the space reach its full potential. 
In this paper, the creation of a new classroom at the UPV is introduced. The new classroom has been baptised as "the classroom of the future" and was inspired by the Princeton experience, although a participative bottom to top process has been done to incorporate the users (students, professors) and UPV' staff (such as pedagogues or health and safety personnel) views. Section 2 describes the workshops hosted at the UPV and the results obtained whereas section 4 presents the proposed design. Finally, section 5 contains the main conclusions of this work.

\section{METHODOLOGY}

To get the users' views three workshops were organized. The goal of the first two workshops was to define the main general requirements of the classroom. The third workshop was designed to, in addition, end up with the design of a reduced scale prototype of the classroom of the future.

\subsection{Defining the classroom requirements}

To define the classroom requirements two workshops with two different focus groups were organised. The first one was attended by students from a fourth year course called "Structural Systems. The second one was attended by professors, university staff -e.g. staff in charge of the health and safety and the building maintenance as well as staff from the Institute of Educational Sciences- and school furniture manufacturers. The goal of both workshops was to define the general requirements that the new classroom should have.

In both workshops a concept mapping (CM henceforth) tool was used to identify the main attributes clustered into categories related to the classroom. At the same time, the workshops also served to identify competences that had to be developed in the classrooms.

$\mathrm{CM}$ is a general method that can be used to help to describe ideas about some issues in a pictorial form. CM is a structured process, focused on a critical issue of interest, involving input from one or more participants, that produces an interpretable pictorial view (called concept map) of their ideas and how these are interrelated [3]. Fig. 1 shows an image of the workshop held with university staff. Details on how this methodology was applied are given in Paya-Zaforteza et al [4] and are not repeated here. Table 1 shows the crucial attributes of the new classroom for each one of the groups.

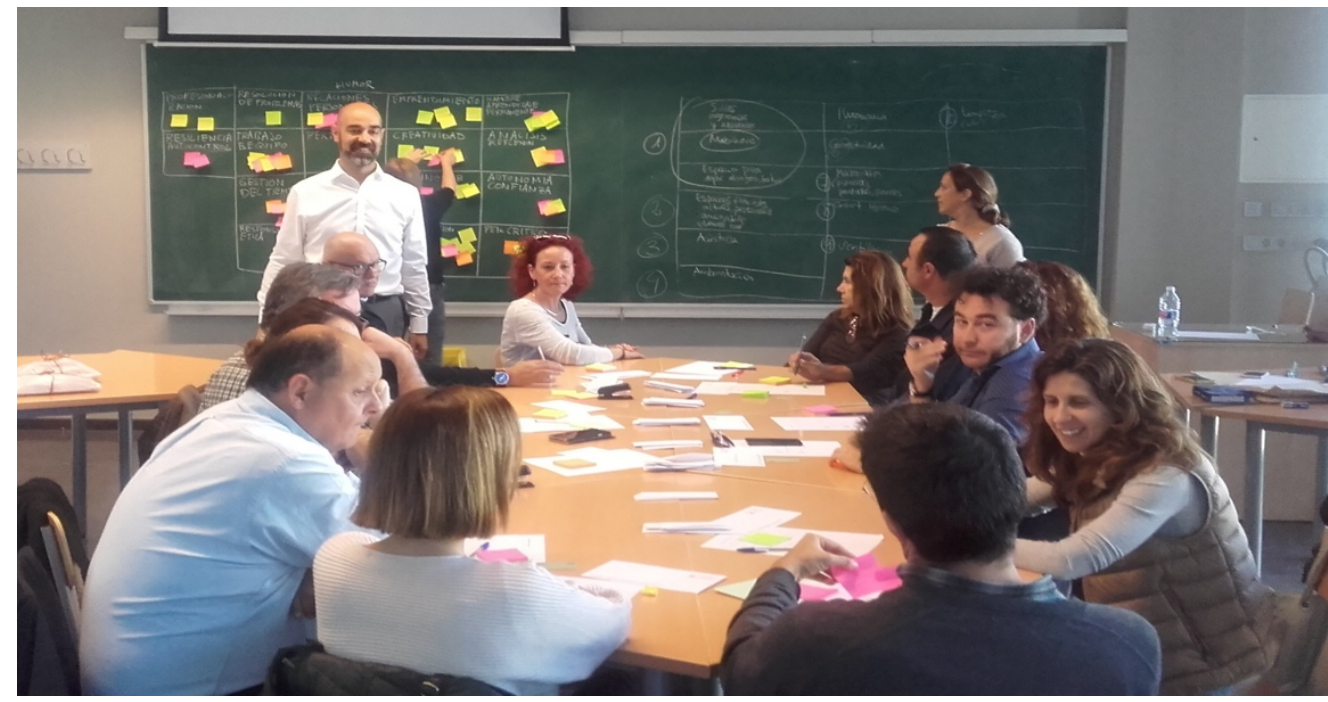

Figure 1. Workshop with professors, university staff and furniture manufacturers. 
Table 1. Crucial attributes in classroom design derived from multidisciplinary experts focus group. The order in which they appear has no special significance.

\begin{tabular}{c|c|c}
\hline \hline & Students & $\begin{array}{c}\text { Professors, University staff and furniture } \\
\text { manufacturers }\end{array}$ \\
\hline 1 & Acoustics & Furniture \\
\hline 2 & Rest Zone & Flexible space \\
\hline 3 & Furniture & Acoustics \\
\hline 4 & Room distribution & Ambiance \\
\hline 5 & Images \& Colors & Proper lighting \\
\hline 6 & Interaction & Connectivity \\
\hline 7 & Craft \& Boards & Material resources \\
\hline 8 & Illumination & Thermal comfort \\
\hline 9 & Material resources & Good ventilation \\
\hline 10 & Air conditioning & Cleaning \\
\hline 11 & High ceilings & - \\
\hline 12 & Outdoor & \\
\hline \hline
\end{tabular}

\subsection{Building the prototypes of the classroom of the future}

The third workshop was attended by students of different UPV degrees and was organised in two sessions, each session being four hours long. The workshop took place at the place that had to be transformed into the classroom of the future.

In the first session, the students were divided in two groups. Some icebreaking activities as well as some creative techniques (6-3-5, Scenario design, POV, customer journey map) were used to make the groups propose their "Decalogue of the classroom of the future". During the session, the professors also gave some short talks on important topics for classroom design such as ergonomics, accessibility, usability and inclusion. Details on the creative techniques used and the talks content is given in Fuentes-Durá et al. [5] and is not repeated here. Table 1 summarizes the Decalogue proposed by the two participating groups.

Table 2. Decalogue of the classroom of the future.

\begin{tabular}{|c|c|c|}
\hline & Team A & Team B \\
\hline 1 & $\begin{array}{l}\text { Easily moveable furniture that supports } \\
\text { quick changeovers and varying } \\
\text { instructional practices }\end{array}$ & $\begin{array}{l}\text { Differentiated spaces for different type } \\
\text { of activities. }\end{array}$ \\
\hline 2 & Visual and interactive learning & Freedom of action. \\
\hline 3 & Make the most of natural light & Music. \\
\hline 4 & $\begin{array}{l}\text { Flexible space to allow individual/ } \\
\text { group tasks }\end{array}$ & Aromatherapy and color therapy. \\
\hline 5 & $\begin{array}{l}\text { Direct or indirect interaction with } \\
\text { natural world }\end{array}$ & $\begin{array}{l}\text { Variated furniture. Different seats and } \\
\text { regulable height. }\end{array}$ \\
\hline 6 & $\begin{array}{c}\text { Direct or indirect interaction with } \\
\text { external world }\end{array}$ & $\begin{array}{c}\text { Comfort. Regulable temperature and } \\
\text { ventilation. }\end{array}$ \\
\hline 7 & Spatial hierarchy attending to function & Leisure area. \\
\hline 8 & Storage space & Personalizable. \\
\hline 9 & Ergonomic furniture & Technology. \\
\hline 10 & Accesibility & Accesibility. \\
\hline
\end{tabular}


In the second session, which also was four hours long, the teams used their Decalogue to build a prototype. They had the freedom to choose the material and scale. Team A created a foam core based model whereas Team $B$ used mainly building blocks toys. The resulting prototypes can be seen in Fig. 2. Both of them "break" the traditional structure of a classroom and share important features such as:

- Movable furniture is used to create a flexible space.

- Walls are panelled with cork so information can be shared with colleagues and reviewed by professors publicly.

- A leisure zone at the end of the classroom is created to help the relaxation of students thanks to natural elements such plants so as to create a direct connection with the external world.

- Shelves are included to enable the storage of backpacks, skates or any other item the students might bring to the classroom.

- No elevated platform is allowed in the classroom.

The session also brought to light the important role of connectivity in present day classrooms. The students insisted on the importance of having a good Wi-Fi connection and plugs for their devices. Placing the plugs in the middle of the classroom to make them compatible with the flexible use of the space seems especially challenging, since the floor cannot removed to place required wires and having the plugs hanging from the roof would seriously affect the aesthetics and the functionality of the classroom.

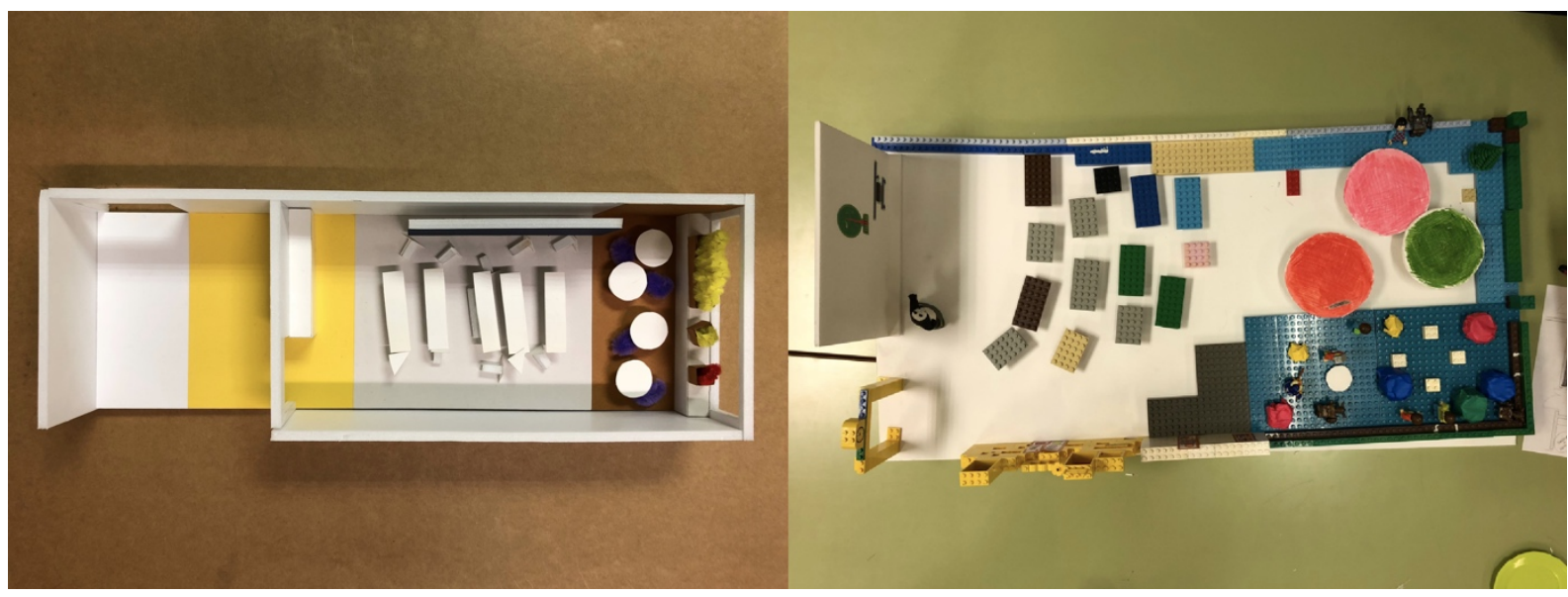

Figure 2. Models of the ideal layout of the future classroom. Team A foam core based model (left) and Team B building blocks toys based model (right).

Even though proposals were very creative and innovative at the beginning, they became more realistic while models were being built. For example, electrical wiring under the floor to provide multiple plug options was discarded as elevating the floor was thought too expensive. An aerial system was rejected as wiring could disturb the visuals.

Technology issues were suggested and debated even though they were not represented in the models. For instance, proper wifi were considered crucial. The possibility of every student being able to connect with the main projector was proposed so as to share information and to promote collaborative creation during the lessons.

\section{RESULTS}

Finally, and having in mind the input from all the workshops as well as the economic constraints of the project, a proposal for the new classroom was developed. This proposal includes shelves at the entrance, movable furniture, painted-wall blackboards instead of traditional blackboards, walls panelled with cork, a small leisure zone and foldable tables. Fig. 3 shows a plan view of the classroom with its main elements as well as two different possibilities for furniture distribution. 


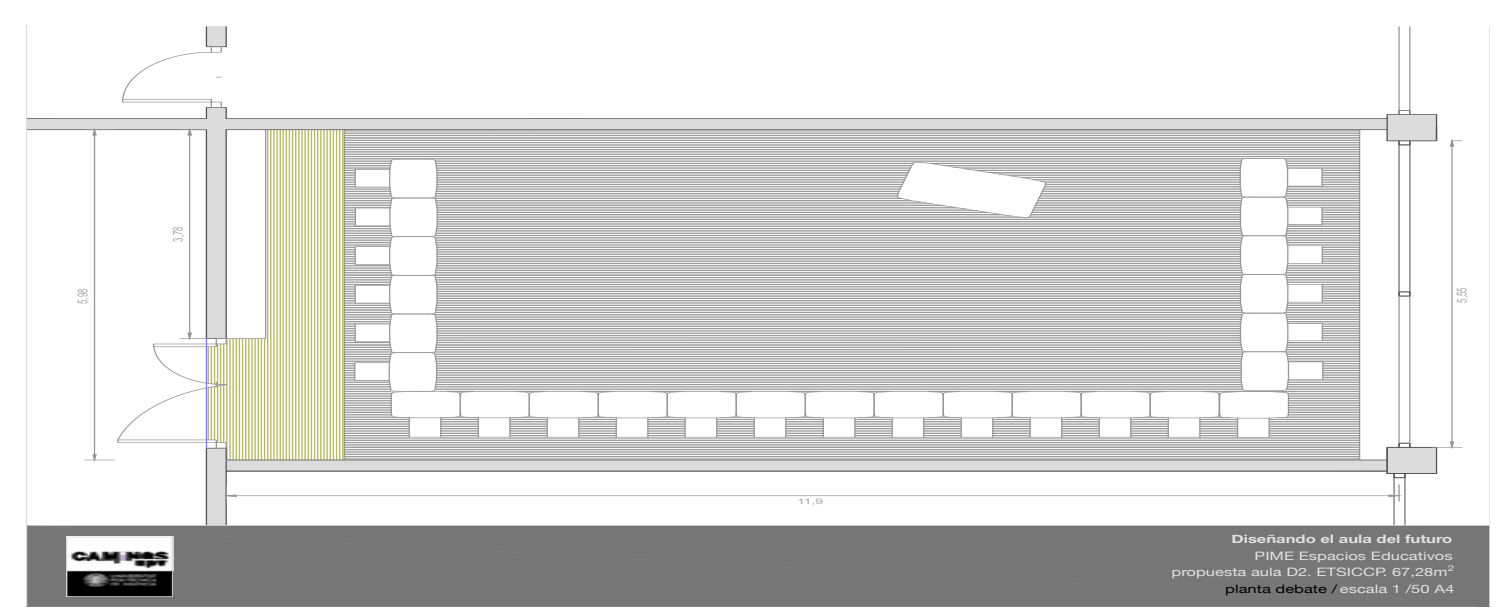

Figure 3. Plan views of the classroom showing its main elements as well as two possibilities for the furniture distribution.

\section{CONCLUSIONS}

This paper shows the methodology used to define a new learning space at the School of Civil Engineering of the Universitat Politècnica de València in Spain. The design principles of the classroom have been defined using a bottom to top approach. The new design is now under implementation and should be ready for use for the first term of the course 2019-2020.

\section{ACKNOWLEDGEMENTS}

The authors wish to express their gratitude to Instituto de Ciencias de la Educación (Institute for Education Sciences) and the School of Civil Engineering of the UPV for all the support received. Authors also want to thank the contribution of all the workshop participants.

\section{REFERENCES}

[1] European Commission. The Bologna Process and the European Higher Education Area. https://ec.europa.eu/education/policies/higher-education/bologna-process-and-european-highereducation-area_en . Accessed on 17/01/2019.

[2] M.E.M. Garlock, I. Paya-Zaforteza. "The structural playground, a new environment where to enjoy learning structural engineering". IABSE Conference, Geneva 2015: Structural Engineering: Providing Solutions to Global Challenges - Report, pp. 336-339, 2015.

[3] M. Kane, and W.M.K. Trochim, W. M. K. "Applied social research methods series. Concept mapping for planning and evaluation".Thousand Oaks, CA, US: Sage Publications, Inc., 2007.

[4] I. Payá Zaforteza, I. Kuster Boluda, N.M. Vila López, and P. Fuentes-Durá "FURTHER DEVELOPMENT OF LEARNING SPACES THROUGH CONCEPT MAPPING". ICERI Proceedings, pp. 5119-5128, 2018.

[5] P. Fuentes-Durá, N. Matarredona-Desantes, T.M. Pellicer Armiñana, S. Asensio Cuesta, and I. Payá Zaforteza "CREATING THE CLASSROOM OF THE FUTURE THROUGH CO-CREATION". ICERI Proceedings, pp. 5129-5135, 2018. 